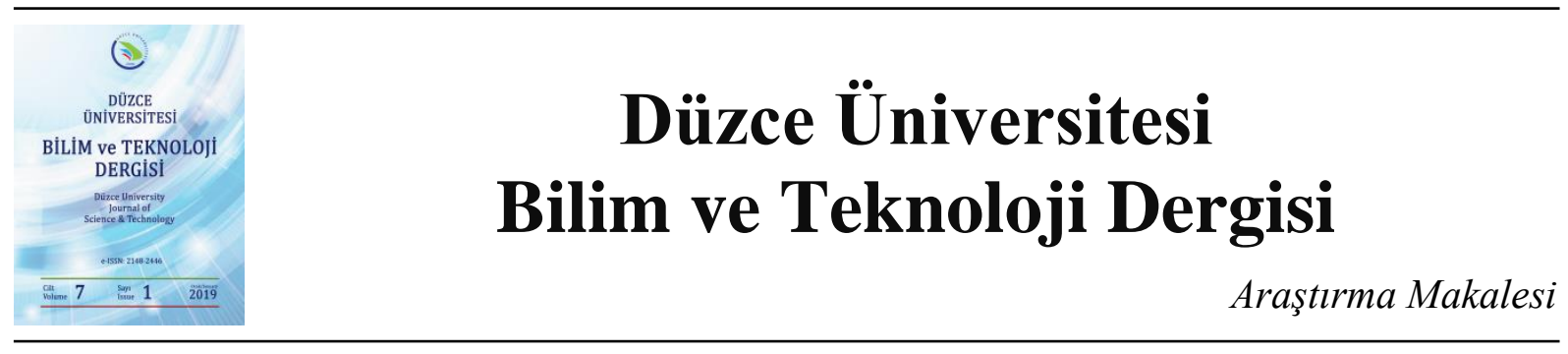

\section{Taguchi Yöntemi ile Nokta Direnç Kaynaklı TWIP Çeliklerin Dayanım Optimizasyonu}

\author{
Hayriye ERTEK EMRE ${ }^{\mathrm{a},{ }^{*}}$ \\ ${ }^{a}$ İmalat Mühendisliği Bölümü, Teknoloji Fakültesi, Karabük Üniversitesi, Karabük, TÜRKIYE \\ * Sorumlu yazarin e-posta adresi : hayriyeertek@karabuk.edu.tr
}

\begin{abstract}
ÖZET
İleri yüksek mukavemetli çeliklerin (Advanced High Strength Steel-AHSS) üyelerinden biri olan TWIP (TWinning Induced Plasticity- İkizlenmeyle plastisite kazanan) çeliklerin mikroyapı ve mekanik özellikleri, kaynak ve isıl işlem gibi yüksek termal döngülerden etkilenirler. Bu çalışmada, mukavemet ve kaynak çekirdek geometrisinin optimizasyonu için çeşitli kaynak parametrelerinde TWIP çelik saclar nokta direnç kaynağı ile birleştirilmiştir. $\mathrm{Bu}$ amaçla, deney numunelerinin çekme makaslama dayanımı ve kaynak çekirdek çapının optimizasyonu Taguchi deneysel tasarım yöntemi kullanılarak belirlenmiş ve $\mathrm{L}_{9}$ ortogonal dizini seçilmiştir. Analiz test sonuçlarına dayanarak, Taguchi analiziyle belirlenen nokta direnç kaynaklı TWIP çeliği için en iyi mukavemet ve kaynak çekirdek kalitesini veren optimum kaynak parametresi, 7 kA kaynak akımı ve 20 çevrim kaynak zamanı (A2B3) olarak belirlenmiştir. Çekme makaslama dayanımının etki eden en önemli kaynak parametresi kaynak akımı iken, kaynak çekirdek çapı değeri için en etkili değişkenin kaynak zamanı olduğu belirlenmiştir.
\end{abstract}

Anahtar Kelimeler: TWIP çelikleri, Taguchi metodu, Çekme makaslama dayanımı, Kaynak çekirdek çapı

\section{Strength Optimization of Resistance Spot Welded TWIP Steel by Taguchi Method}

\begin{abstract}
The microstructure and mechanical properties of TWIP (TWinning Induced Plasticity) sheets, one of the members of Advanced High Strength Steel (AHSS), are affected by excessive thermal cycles such as welding and heat treatment. In this study, TWIP steel sheets are joined with the resistance spot weld in various welding parameters for optimization of the strength and weld nugget geometry. For this purpose, the optimization of the tensile shear strength and weld nugget diameter of the weldments were determined by using Taguchi experimental design method and L9 orthogonal array was chosen. Based on the analysis test results, the optimum welding parameter which provides the best strength and weld nugget quality for the resistance spot welded TWIP steel was determined by Taguchi analysis as $7 \mathrm{kA}$ welding current and 20 cycle welding time (A2B3). It has been determined that the most effective variable for weld nugget diameter value is welding time, while the most important welding parameter for effecting tensile shear strength is the welding current.
\end{abstract}

Keywords: TWIP steels; Taguchi method; Tensile shear strength; Weld nugget diameter 


\section{GiRiș}

$\mathrm{O}$ tomotiv endüstrisinde yaygın olarak kullanılan gelişmiş yüksek mukavemetli çelikler (AHSS) arasında en sık kullanılan çelik türleri DP, TRIP ve TWIP'dir. AHSS çelikleri nokta direnç kaynağı sonrası daha küçük bir kaynak çekirdek oluşumu ve arayüzey şeklinde kırılmaların meydana gelmesi nedeniyle sinırlı bir kaynaklanabilirliğe sahiptir [1,2].

Nokta direnç kaynağında (NDK) en iyi kaynaklanabilirlik koşulları optimum kaynak çekirdek geometrisi ve en yüksek çekme makaslama dayanımının elde edilmesi ile sağlanır [3-5]. Kaynak çekirdek boyutu mekanik özelliklerin belirlenmesinde oldukça önemli bir rol teşkil etmektedir [6-8]. Kullanılan çelik sac kalınlığına bağlı olarak istenilen minimum kaynak çekirdek çapı $\left(d_{n}\right)$, AWS, ANSI/SAE (American Welding Society/American National Standards Institute/Society of Automotive Engineers ) gibi çeşitli endüstriyel standartlarca $d_{n}=4 \sqrt{t}(t=s a c$ kalınlığ $1, m m)$ denklemine göre belirtilmiştir [9]. Ancak bu formül her zaman en iyi dayanım koşullarını sağlamamaktadır. Bu nedenle, en uygun çekme makaslama dayanımı için uygun kaynak parametrelerini seçmek önemlidir. Girdi parametreleri ile çıktı değişkenleri arasındaki ilişkiyi belirlemek için matematiksel modeller geliştirerek istenen çıktı değişkenlerini tanımlamak için çeşitli optimizasyon yöntemleri uygulanabilir $[10,11]$. Deneysel olarak optimum şartları belirlemek için çok fazla işlem yapmak gerekir ve bu da hem zaman hem maliyet açısından istenmeyen bir durumdur [12]. Taguchi tasarım metodu, proses parametrelerini optimize etmek için basit, düşük maliyetli ve sağlam bir tekniktir [13-17]. Literatürde Taguchi analizi ile ilgili birçok araştırma mevcuttur. Bu analiz yöntemi ağırlıklı olarak optimum işleme koşulları, işleme parametrelerine bağlı olarak yüzey pürüzlülüğü, yüzey aşınması vb. özelliklerinin araştırılmasında ve kaynak parametrelerinin optimizasyonunda kullanılmaktadır [14-21]. Eşme vd.[22] SAE 1010 çelik sacların nokta direnç kaynağında, kaynak parametreleri değişiminin mukavemete etkilerini Taguchi yöntemi kullanarak incelemişlerdir. Çalışma neticesinde kaynak mukavemetine etki eden en önemli kaynak değişkeninin sırasıyla elektrot kuvveti, elektrot çapı, kaynak akımı ve kaynak zamanı olduğu belirtmişlerdir. Başka bir çalışmada, Mukhopadhyaya vd. [23] kaynak çekirdek çapının, yükleme kuvveti ve alaşım kimyası değişiminin IF çeliklerinin nokta direnç kaynaklarının mukavemetine olan etkilerini Taguchi analiz yöntemi kullanarak incelemişlerdir. Sonuçlar, IF çeliklerinin nokta direnç kaynaklarında kaynak çekirdek çapının artışına bağlı olarak mukavemet değerlerinin arttığını göstermiştir. Thakur vd. [24] galvanizli çeliklerin nokta direnç kaynaklı birleştirmelerinde, kaynak parametrelerinin optimizasyonunun çekme makaslama dayanımı değişimine etkisinin araştırılmasında Taguchi yöntemi kullanmışlardır. Deney sonuçlarında, nokta direnç kaynağında kaynak parametrelerinin optimizasyonu ve kaynak kalitesinin artırılmasında Taguchi yönteminin geçerliliğini doğruladığını rapor etmişlerdir.

TWIP çeliğinin optimum koşullarda nokta direnç kaynaklanabilirliği ile ilgili yetersiz bilgi birikimi nedeniyle, otomotiv üreticileri tarafindan yaygın bir şekilde kullanılamamaktadır [25]. Bu çalışmada, optimum çekme makaslama dayanımının ve en uygun kaynak çekirdek çapının istatistiksel olarak değerlendirilmesi Taguchi tasarım metodu ile gerçekleştirilmiştir. Kaynak parametrelerinin önemli seviyeleri de varyans analizi (ANOVA) kullanılarak elde edilmiştir. 


\section{MALZEME VE YÖNTEM}

Çalışmada kullanılan $1 \mathrm{~mm}$ sac kalınlığındaki TWIP çeliğinin spektral analiz sonucu elde edilen kimyasal bileşimi Tablo 1'de verilmiştir. Deney numuneleri 5,5 mm çapa sahip F16 uçlu Cu-Cr-Zr elektrot kullanılarak $50 \mathrm{~Hz}$ elektrik devresinde $60 \mathrm{kVA}$ kapasiteli bir pnömatik nokta direnç kaynak makinesinde birleştirilmiştir. Çekme makaslama deney numuneleri ANSI/AWS/SAE/D8.9-97 standardına uygun olarak hazırlanmıştır [9].

Tablo 1. TWIP çeliğinin kimyasal bileşimi (\% ăgırlık)

\begin{tabular}{lllllll}
\hline & C & Si & Mn & B & Al & Fe \\
\hline TWIP & 0,024 & 2,36 & 32 & $<0,01$ & 3,16 & Kalan \\
\hline
\end{tabular}

Tüm deneyler için elektrot kuvveti $(6 \mathrm{kN})$, sıkıştırma zamanı ( 25 çevrim, 1 çevrim $=0.02 \mathrm{sn})$ ve tutma zamanı (15 çevrim) kaynak parametreleri sabit tutulmuştur. Tablo 2'de her bir faktör için kaynak akımı ve kaynak zamanı seçilmiştir. Taguchi yöntemi, Tablo 3'te gösterildiği gibi Minitab 17 yazılımı ile L 9 ortogonal dizi kullanılarak gerçekleştirilmiştir.

Tablo 2. Faktörlerin Seviyeleri

\begin{tabular}{llllll}
\hline Sembol & NDK parametresi & Birim & Seviye 1 & Seviye2 & Seviye 3 \\
\hline A & Kaynak akım1 & $k A$ & 5 & 7 & 9 \\
\hline B & Kaynak zaman1 & çevrim & 15 & 20 & 25 \\
\hline l çevrim=0,02 sn & & & & \\
\hline
\end{tabular}

Her bir kaynak parametresi için üç adet çekme makaslama testi gerçekleştirilmiş ve ortalama değerleri hesaplanmıştır (Şekil 1a). Testler, $10 \mathrm{~mm} /$ dak sabit çekme hızında $50 \mathrm{kN}$ kapasiteli SHIMADZU çekme test makinesi ile gerçekleştirilmiştir. Kaynak çekirdek çapı $d_{n}(m m)$, deney numunelerinin enine kesitinden ölçülmüştür (Şekil 1 b).

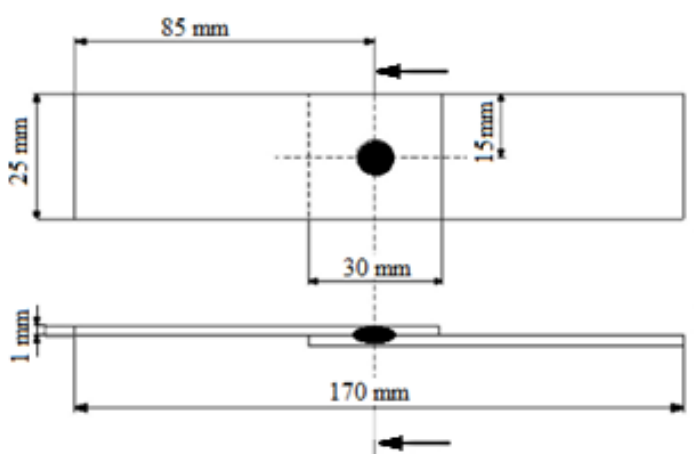

a)

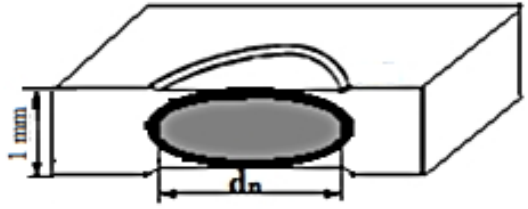

b)

Şekil 1. (a) Çekme makaslama numunesi ve (b) Kaynak kesiti görüntüsü

Taguchi yöntemi, sonuç verilerini sinyal/gürültü (S / N) oranına dönüştürür [26,27]. Bu çalışmada, maksimum çekme makaslama dayanımı ve kaynak çekirdek çapının elde edilmesi için S / N oranı, Eşt. 1 'de gösterildiği gibi "en büyük en iyi” kriterine göre de seçilmiştir [14]. 


$$
\eta=S / N=-10 \log \left(\frac{1}{n} \sum_{i=1}^{n} \frac{1}{y_{i}^{2}}\right), \mathrm{i}=1,2 \ldots . \mathrm{k}
$$

Burada, $y_{i}$ her deney sonucunda elde edilen veriyi, $n$ ise deney sayısını göstermektedir. Farklı kaynak parametrelerinin etkisi, varyans analizi (ANOVA) ile belirlenmiştir. Tahmini deney verileri ve deneysel veriler karşılaştırılmıştır.

\section{DENEYSEL SONUÇLAR}

Ortalama çekme makaslama dayanımının, kaynak çekirdek çapının $\left(d_{n}\right)$ ve $S$ / $N$ oranlarının ortalama değerleri Tablo 3 'te gösterilmiştir.

Tablo 3. Nokta direnç kaynaklı TWIP çeliği deney sonuçları ve S/N oranları

\begin{tabular}{|c|c|c|c|c|c|c|}
\hline \multicolumn{3}{|c|}{ Kaynak parametreleri } & \multicolumn{2}{|c|}{$\begin{array}{l}\text { Çekme makaslama } \\
\text { Dayanımı (ÇMD) }\end{array}$} & \multicolumn{2}{|c|}{ Kaynak çekirdek çapı $\left(d_{n}\right)$} \\
\hline $\begin{array}{l}\text { Deney } \\
\text { no }\end{array}$ & $\begin{array}{c}\text { Kaynak } \\
\text { Akımı } \\
(k A)\end{array}$ & $\begin{array}{l}\text { Kaynak } \\
\text { Zamanı } \\
\text { (çevrim) }\end{array}$ & $\begin{array}{c}\text { Ortalama } \\
\text { ÇMD } \\
(M P a)\end{array}$ & $\begin{array}{c}\mathbf{S} / \mathbf{N} \\
\text { oranı } \\
(d B)\end{array}$ & $\begin{array}{c}\text { Ortalama } \\
\mathbf{d}_{\mathbf{n}} \\
(\mathrm{mm})\end{array}$ & $\begin{array}{c}\mathbf{S} / \mathbf{N} \\
\text { oranı } \\
(d B)\end{array}$ \\
\hline 1 & 5 & 15 & 8,7 & 18,7904 & 4,30 & 12,669 \\
\hline 2 & 5 & 20 & 9,4 & 19,4626 & 5,10 & 14,151 \\
\hline 3 & 5 & 25 & 9,5 & 19,5545 & 5,20 & 14,320 \\
\hline 4 & 7 & 15 & 10,7 & 20,5877 & 4,50 & 13,064 \\
\hline 5 & 7 & 20 & 12 & 21,5836 & 5,50 & 14,807 \\
\hline 6 & 7 & 25 & 12,5 & 21,9382 & 7,00 & 16,902 \\
\hline 7 & 9 & 15 & 9,7 & 19,7354 & 4,49 & 13,044 \\
\hline 8 & 9 & 20 & 9,9 & 19,9127 & 5,60 & 14,963 \\
\hline 9 & 9 & 25 & 10,2 & 20,1720 & 6,75 & 16,586 \\
\hline
\end{tabular}

Tablo 4'te her bir parametre için $\mathrm{S} / \mathrm{N}$ oranları ortalaması, toplam ortalama $\mathrm{S} / \mathrm{N}$ oranı, maksimum ve minimum değerleri arasındaki fark değerleri (Delta, $\Delta$ ) görülmektedir. Buna ek olarak, $\mathrm{S} / \mathrm{N}$ oran grafikleri Şekil 2'de gösterilmiştir.

Tablo 4. S/N oranları tablosu

\begin{tabular}{|c|c|c|c|c|c|c|c|c|}
\hline \multirow[t]{2}{*}{ Testler } & \multirow[t]{2}{*}{ Sembol } & \multirow{2}{*}{$\begin{array}{l}\text { Kaynak } \\
\text { Parametreleri }\end{array}$} & \multirow[t]{2}{*}{ Birim } & \multicolumn{3}{|c|}{$\underline{\mathrm{S} / \mathrm{N} \text { oranı }}$} & \multirow{2}{*}{$\begin{array}{c}\text { Toplam } \\
\text { Ort.S/N } \\
(d B)\end{array}$} & \multirow{2}{*}{$\begin{array}{c}\text { Delta } \\
(\Delta)\end{array}$} \\
\hline & & & & Seviye 1 & Seviye 2 & Seviye 3 & & \\
\hline Çekme & A & Kaynak akımı & $k A$ & 19,27 & $* 21,37$ & 19,94 & & 2,10 \\
\hline Makaslama & & & & & & & 20,19 & \\
\hline $\operatorname{Dayanımı}(k N)$ & B & Kaynak zamanı & çevrim & 19,70 & 20,32 & $* 20,55$ & & 0,85 \\
\hline \multirow{2}{*}{$\begin{array}{l}\text { Çekirdek çapı } \\
(m m)\end{array}$} & $\mathrm{A}$ & Kaynak akımı & $k A$ & 13,71 & $* 14,92$ & 14,86 & & 1,21 \\
\hline & B & Kaynak zamanı & çevrim & 12,93 & 14,64 & $* 15,94$ & 14,50 & 3,01 \\
\hline
\end{tabular}




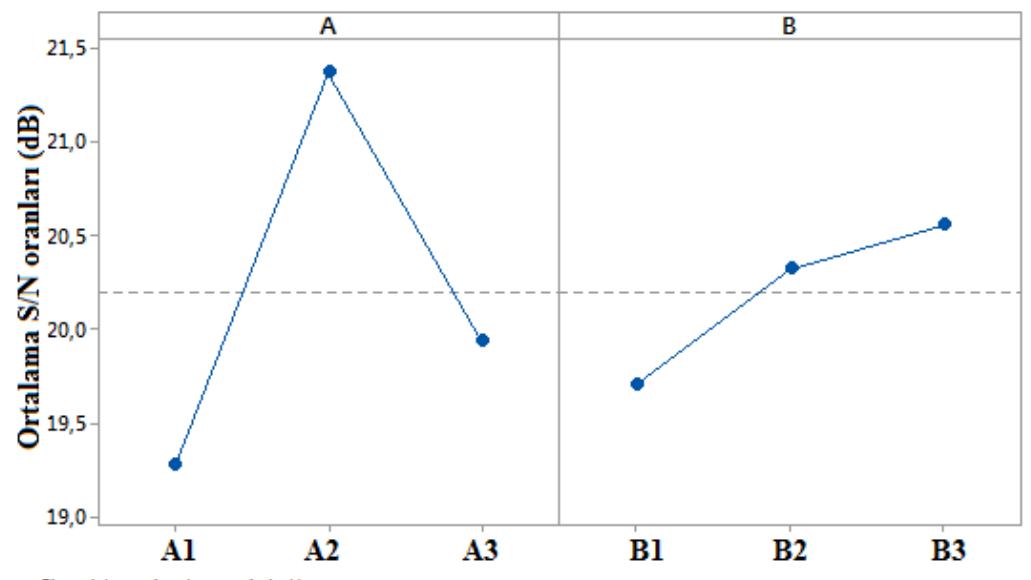

(a)

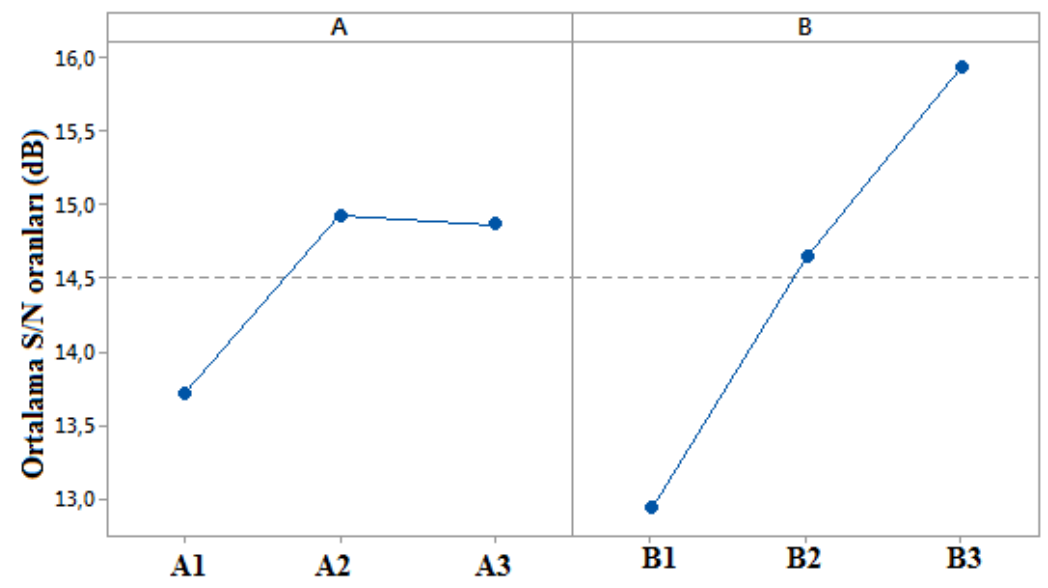

(b)

Şekil 2. (a) Çekme makaslama dayanımı ve (b) Kaynak çekirdek çapı için, kaynak parametrelerinin S/N oranları

Tablo 4 'ten görüldüğü üzere (*) ile işaretlenen maksimum $\mathrm{S} / \mathrm{N}$ oranı değerleri, maksimum çekme makaslama dayanımı için A2B3 ve maksimum kaynak çekirdek çapı için A2B3 olarak belirlenmiştir. Yani, maksimum değerlere $7 \mathrm{kA}$ kaynak akımı ve 20 çevrim kaynak zamanında ulaşıldığı anlamına gelmektedir. Tutar, vd.[28], soğuk haddelenmiş TWIP çeliklerinin nokta direnç kaynağı ile birleştirmelerinde rastgele yaklaşımlı Taguchi metodu kullanarak, kaynak parametrelerinin optimizasyonunu gerçekleştirmişlerdir. Yapılan deneyler sonucu en yüksek kopma yükünü sağlayan kaynak parametrelerinin 6 kA kaynak akımı, 250 ms kaynak zamanı ve $2250 \mathrm{~N}$ elektrot baskı kuvveti olduğu belirtilmiştir.

Şekil 2 a ve b'den görüldüğü gibi çekme makaslama dayanımı ve kaynak çekirdek çapı A parametresi (kaynak akımı) için A1'den A2'ye (5kA'dan 7kA'ya) kadar arttıkça artış göstermekte, 7kA kaynak akım değeri üzerinde ise azalma meydana gelmektedir. Bu durumun sebebinin, belirli bir kaynak akım şiddetinin üzerinde aşırı 1sı girdisine bağlı olarak kaynak çekirdeğinin aşırı ergime ve daha fazla fışkırmaya bağlı kaynak çekirdek boyutunun azalması, kaynak kesiti incelmesi ve buna bağlı olarak dayanımın düşmesi olduğu belirtilmektedir. Kaynak çekirdek çapı değişiminin, çekme makaslama dayanımını ile paralel bir şekilde değişim gösterdiği belirtilmektedir [29]. B1'den B2 ve B3'e doğru bir artış gösteren B parametresi için (kaynak zamanı) çekme makaslama dayanımı ve çekirdek çapı 
değerlerinin arttı̆̆ görülmektedir. Varyans analizi (ANOVA) sonuçları \% 95 güvenirlik düzeyinde Tablo 5 ve 6' da verilmiştir. Burada, her bir değişkenin sonuçlar üzerindeki serbestlik derecesini gösteren SD değerleriyle, kareler toplamı (KT), kareler ortalaması (KO), F değerleri ve yüzde katkı oranları (PRC) görülmektedir. PRC değerleri grafiksel olarak Şekil 3a ve b'de gösterilmiştir.

Tablo 5. Çekme makaslama dayanımı S/N oranları için varyans analizi(ANOVA) sonuçları

\begin{tabular}{lllllll}
\hline Sembol & $\begin{array}{l}\text { Kaynak } \\
\text { parametreleri }\end{array}$ & SD & KT & KO & F & $\begin{array}{l}\text { Katki } \\
\text { Yüzdesi } \\
\text { (PRC) }\end{array}$ \\
\hline A & Kaynak akımı & 2 & 6,9073 & 3,45366 & 51,53 & 82,9 \\
B & Kaynak zamanı & 2 & 1,1569 & 0,57845 & 8,63 & 13,9 \\
& Hata & 4 & 0,2681 & 0,06702 & & 3,2 \\
& Toplam & 8 & 8,3323 & & & \\
\hline
\end{tabular}

Tablo 6. Kaynak çekirdek çapı S/N oranları için varyans analizi(ANOVA) sonuçları

\begin{tabular}{ccccccc}
\hline Sembol & $\begin{array}{c}\text { Kaynak } \\
\text { parametreleri }\end{array}$ & SD & KT & KO & F & $\begin{array}{c}\text { Katkı } \\
\text { Yüzdesi } \\
\text { (PRC) }\end{array}$ \\
\hline A & Kaynak akımı & 2 & 2,795 & 1,3976 & 3,40 & 15,4 \\
B & Kaynak zamanı & 2 & 13,677 & 6,8384 & 16,66 & 75,5 \\
& Hata & 4 & 1,642 & 0,4106 & & 9,1 \\
& Toplam & 8 & 18,114 & & & \\
\hline
\end{tabular}

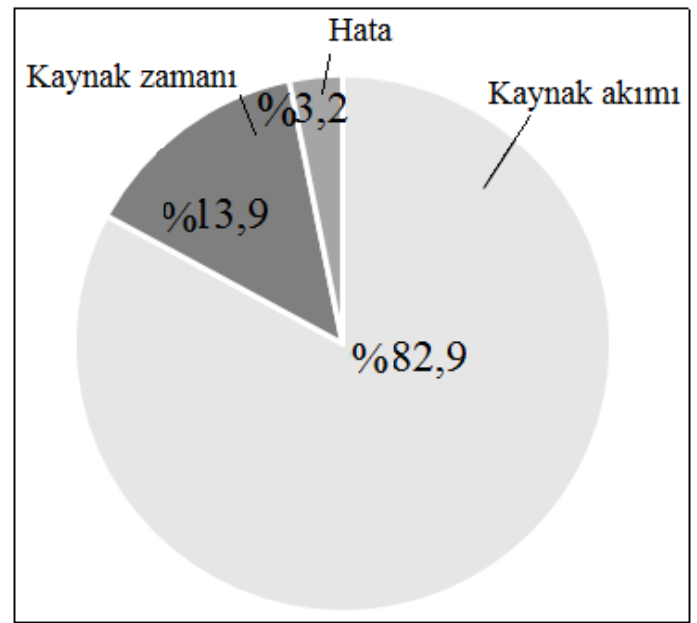

(a)

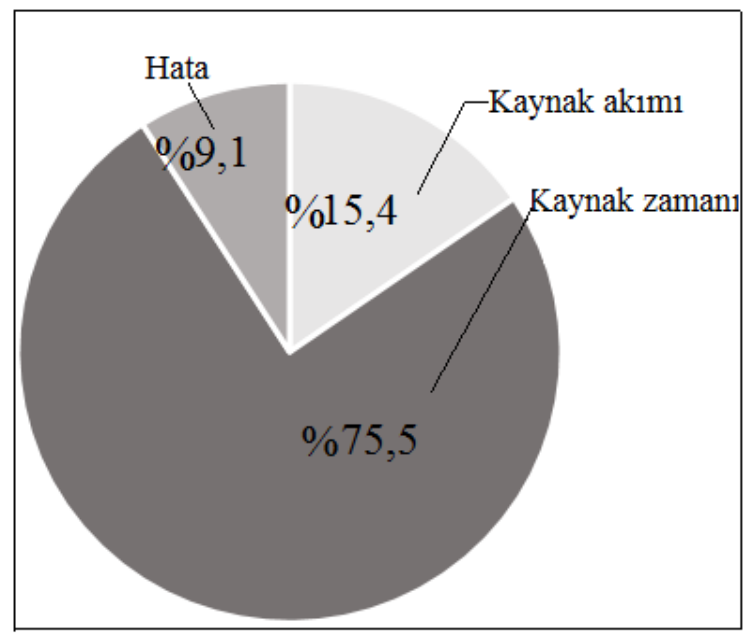

(b)

Şekil 3. Kaynak parametrelerinin (a) Çekme makaslama dayanımı ve (b) Kaynak çekirdek çapı için PCR oran grafiği

Tablo 5,6 ve Şekil 2, çekme makaslama dayanım değeri için en etkili değişkenin\% 82,9'luk PCR ile kaynak akımı olduğunu göstermektedir. Benzer şekilde nokta direnç kaynaklı bağlantıların Taguchi 
metodu ile optimizasyonunda çekme makaslama dayanımını etkileyen en önemli parametrenin kaynak akımı olduğu belirtilmektedir [28]. Diğer taraftan, kaynak çekirdek çap1 değeri için en etkili değişkenin \% 75,5'lik PCR ile kaynak zamanı olduğu belirlenmiştir. Optimizasyon işleminde varyans analizi (ANOVA) sonrası uygulanacak olan işlem, sonuçların doğrulanmasını test etmek amacıyla doğrulama deneylerinin gerçekleştirilmesidir. Optimizasyon sonrası tahmin edilen seviyeler, deneysel çalışmalar arasından birisi ise doğrulama deneylerine gerek duyulmaksızın, optimizasyon performansı belirlenebilmektedir [30]. Bu çalışmada, çekme makaslama dayanımı ve kaynak çekirdek çapı için tahmin edilen optimal seviyeler yapılan deneyler içerisinde mevcuttur.

Tablo 7'de tahmini Taguchi analiz sonuçlarının ve deneysel sonuçların karşılaştırılması verilmiştir. Çekme makaslama dayanımı ve kaynak çekirdek çapı tahmini için yapılan analiz sonuçları ile doğrulama deneyleri sonuçlarının S/N oranları dikkate alınırsa, farkın oranının çekme makaslama dayanım değerleri için yaklaşık 0,2 ve kaynak çekirdek çapı için daha da az olup 0,009 değerinde olduğu görülmektedir. Taguchi optimizasyonunun kaynak çıktılarının performans karakteristiklerinin belirlenmesinde uygulanan basit ve güvenilir bir yöntem olduğu bir kez daha kanıtlanmıştır.

Tablo 7. Doğrulama deney sonuçları

\begin{tabular}{cccc}
\hline & \multicolumn{2}{c}{ Optimum parametreler } & \\
\cline { 2 - 3 } & Tahmin edilen & Deneysel & Farklar \\
\cline { 2 - 3 } & & $\mathbf{A 2 B 3}$ & \\
Seviye & $\mathbf{A 2 B 3}$ & $\mathbf{1}$ & \\
Çekme makaslama dayanımı $(k N)$ & 12,1778 & $\mathbf{A 2 B 3}$ & 0,3222 \\
S/N oranı $(d B)$ & 21,7317 & 7,00 & \\
\hline Seviye & $\mathbf{A 2 B 3}$ & 0,2065 \\
Kaynak çekirdek çap1 $(m m)$ & 6,95667 & 0,04333 \\
S/N oranı $(d B)$ & 16,8045 & 16,902 & 0,00975 \\
\hline
\end{tabular}

\section{GENEL SONUÇLAR}

$\mathrm{Bu}$ analiz çalışmasında elde edilen bulgular aşağıdaki şekilde özetlenebilir:

- Deneysel çalışmalarda, daha az deney ile daha verimli sonuçlara ulaşılması için uygulanan Taguchi L9 deney tasarımı ve optimizasyonu TWIP çeliklerinin nokta direnç kaynaklı birleştirme işlemi için başarılı bir şekilde uygulanmıştır.

- Çekme makaslama dayanımı ve kaynak çekirdek çaplarının S/N oranları ortalamaları incelendiğinde optimum seviyelerinin her ikisi içinde aynı olduğu belirlenmiştir. Taguchi analizi ile en uygun çekme makaslama dayanımı ve kaynak çekirdek çapını veren kaynak parametresi, 7kA kaynak akımı ve 20 çevrim kaynak zamanı (A2B3) tespit edilmiştir. 
- Kaynak akımının ve kaynak süresinin, kaynak yapısının çekme makaslama dayanımı için ana kontrol faktörü olan kaynak çekirdek çapını belirgin bir şekilde değiştirdiği sonucuna varılmıştır. Çekme makaslama dayanımı, artan kaynak çekirdek çapının kritik bir seviyeye kadar artmasiyla artar.

- Çekme makaslama dayanımının değiş̧iminde en önemli kaynak parametresi,\% 82,9'luk bir PCR ile kaynak akımı olarak bulunmuştur. Kaynak çekirdek çapı için en önemli kaynak parametresi ise \% 75,5'lik bir PCR ile kaynak zamanı olarak bulunmuştur.

- Elde edilen optimizasyon verileriyle deneysel çalışma verilerinin örtüştüğü görülmektedir.

\section{$\underline{\text { V. KAYNAKLAR }}$}

[1] H. B. Cary, Modern Welding Technology, 3rd ed., Prentice Hall, Upper Saddle River, NJ 1994.

[2] Z. Han, J. E. Indacochea, C. H. Chen, and S. Bhat, "Weld nugget development and integrity in resistance spot welding of high-strength cold-rolled sheet steels", Welding Journal, vol. 72 no. 5, pp. 209, 1993.

[3] H. L. Lin, T. Chou, and C. P. Chou, "Optimization of resistance spot welding process using taguchi method and a neural network", Experimental Techniques, pp. 30-36, 2007.

[4] H. Eisazadeh and M. Hamedi, "New parametric study of nugget size in resistance spot welding process using finite element method", Material and Design, vol.31, pp. 149-157, 2010.

[5] A. G. Thanur and V. M. Nandedkar, "Application of Taguchi method to determine resistance spot welding conductions of austenitic stainless AISI 304", Journal of scientific \& Industrial research, vol. 69, pp. 680-68, 2010.

[6] M. Pouranvari, H.R. Asgari, S.M. Mosavizadch, P. H. Marashi and M. Goodarzi, "Effect of weld nugget size on overload failure mode of resistance spot welds", Science and Technology of Welding and Joining, vol. 12, no. 3, pp. 217-225, 2007.

[7] J. Heuschkel, "The expression of spot-weld properties", Welding Journal, vol. 31, no.10, pp. 931-943,1952.

[8] M. Zhou, H. Zhang and S. J. Hu, "Relationships between Quality and Attributes of Spot Welds" Weld. J., vol. 82, pp. 72-77, 2003.

[9] American Welding Society: "Recommended practices for test methods for evaluating the resistance spot welding behavior of automotive sheet steel materials", ANSI/AWS/SAE/D8 9-97, 1997. 
[10] J. S. Kwak, "Application of taguchi and response surface methodologies for geometric in surface grinding process", International Journal of Machine Tools \& Manufacture, vol. 45, pp. 327$334,2005$.

[11] N. Muhammad, Y.H.P. Manurung, M. Hafidzi, S. K. Abas, G. Tham and E. Haruman, "Optimization and modeling of spot welding parameters with simultaneous multiple response consideration using multi-objective Taguchi method and RSM", Journal of Mechanical Science and Technology, vol. 26, no.8, pp. 2365-2370, 2012.

[12] M. Karabatak and M. Kara, F. "Experimental optimization of surface roughness in hard turning of AISI D2 cold work tool steel”, Journal of Polytechnic, vol. 19, pp. 349-355, 2016.

[13] M. Boy, İ. Çiftci, M. Günay and F. Ozhan, "Application of the Taguchi method optimize the cutting conditions in hard turning of a ring bore", Materials and technology, vol. 49, no.5, pp. 765$772,2015$.

[14] M. Günay and E. Yücel, "Application of Taguchi method for determining optimum surface roughness in turning of high-alloy white cast iron", Measurement, vol. 46, pp. 913-919, 2013.

[15] H. Sing and P. Kumar, "Optimization cutting force for turned part using Taguchi's parameter design approach”, Indian Journal Eng Mater Sci, 12, pp. 97-103, 2015.

[16] A.G. Thakur and V. M. Nandedkar, "Application of Taguchi method to determine resistance spot welding conductions of austenitic stainless AISI 304", Journal of scientific \& Industrial research, vol. 69 , pp. 680-68, 2010.

[17] D. Chandra Saha, S. Han, K.G. Chin, I. Choi and Y. D. Park, "Weldability evaluation and microstructure analysis of resistance-spot-welded High-Mn steel in automotive application", Steel Research Int., vol 83, pp. 1-6, 2012.

[18] F. Kara, "Taguchi optimization of surface roughness and flank wear during the turning of DIN 1.2344 tool steel”, Materials Testing, vol.59, pp. 903-908, 2017.

[19] F. Kara and B.Öztürk, "Comparison and optimization of PVD and CVD method on surface roughness and flank wear in hard-machining of DIN 1.2738 mold steel”, Sensor Review, 2018.

[20] H.L Lin and C.P. Chou "Optimisation of The GTA Welding Process Using The Taguchi Method and a Neural Network", Science and Technology of Welding \& Joining, vol. 11, pp. 120 128, 2006.

[21] S. Pandiarajan, S. Senthil Kumaran , L.A. Kumaraswamidhas and R. Saravanan "Interfacial microstructure and optimization of friction welding by Taguchi and ANOVA method on SA 213 tube to SA 387 tube plate without backing block using an external tool", Journal of Alloys and Compounds, vol. 654, pp. 534- 545, 2016.

[22] U. Eşme, "Application of Taguchi Method for the Optimization of Resistance Spot Welding Process", The Arabian Journal for Science and Engineering, vol.34, pp.519-528,Oct.2009 
[23] G. Mukhopadhyaya, S. Bhattacharya, and K.K. Ray, "Strength assessment of spot-welded sheets of interstitial free steels", Journal of Materials Processing Technology, vol. 209, pp.1995-2007, 2009.

[24] A.G. Thakur, T. E. Rao, M. S. Mukhedkar and V. M. Nandedkar, "Application of Taguchi method for resistance spot welding of galvanized steel", ARPN Journal of Engineering and Applied Sciences, vol. 5, pp. 22-26, 2010.

[25] A. A. Karad, V. S. Shete and N. V. Boraste, "Optimization of resistance spot welding process parameter by taguchi method", International Journal of Engineering Research and General Science, vol. 4, no. 2, pp. 679-684, 2016.

[26] N. K. Singh and Y. Vijayakumar, "Application of Taguchi method for optimization of resistance spot welding of austenitic stainless steel AISI 301L", Innovative Systems Design and Engineering vol. 3, pp.50-62, 2012.

[27] S. Athreya and Y. D. Venkatesh, "Application of taguchi method for optimization of process parameters in improv-ing", The Surface Roughness of Lathe Facing Operation International Refereed Journal of Engineering and Science (IRJES), vol. 1, no. 3, pp. 13-19, 2012.

[28] M. Tutar, H. Aydin, A. Bayram, "Multi objective Taguchi optimization approach for resistance spot welding of cold rolled TWIP steel sheets", IOP Conf. Series: Journal of Physics: Conf. Series, vol. 885, 2017.

[29] M. Pouranvari, S. P. H. Marashi and D. S. Safanama, "Failure mode transition in AHSS resistance spot welds - Part II: Experimental investigation and model validation", Materials Science and Engineering: $A$ vol. 528 , no. 29, pp. $8344-8352,2011$ ).

[30] M. Kurt, Y. Kaynak, B. Bakır, U. Köklü, G. Atakök ve L. Kutlu, “Al 2024- T4 Alüminyumun elmas benzeri karbon (DLC) kaplanmış matkaplarla delinmesinde kesme parametrelerinin deneysel incelenmesi ve taguchi optimizasyonu", 5. Uluslararası Illeri Teknolojiler Sempozyumu (IATS'09), 1315 Mayıs 2009. 